\title{
New mechanism for modulating colour vision
}

\section{Single cones start making a different opsin as young salmon move to deeper waters.}

$E^{2}$ ach cone photoreceptor in the retina responds to light in a limited range of wavelengths, giving it a spectral phenotype. This phenotype is determined by the most prevalent of the photoreceptor's visualpigment proteins (opsins) and is assumed to remain unchanged during an animal's lifetime. Here we show that in the Pacific pink salmon, Oncorhynchus gorbuscha, single cones can switch their spectral phenotype from ultraviolet to blue by regulating the production of the appropriate opsins as the fish grow older. This photoreceptor plasticity may operate to modulate colour vision as the salmon's lifestyle changes.

The vertebrate retina has several spectral types of cone photoreceptor. Each photoreceptor contains a visual pigment that is maximally sensitive to ultraviolet (UV), blue, green or red light ${ }^{1}$ and consists of a protein (opsin) attached to a chromophore (a derivative of vitamin $A_{1}$ or vitamin $\left.A_{2}\right)^{1}$. It is the combined input from cones containing different visual pigments, each with a different spectral phenotype, that allows an animal to perceive colour.

Changes in colour sensitivity in the outer retina arise from altering the density of different cone types ${ }^{2}$ or by switching chromophores (vitamin $\mathrm{A}_{2}$-based visual pigments absorb light of longer wavelengths than their vitamin $A_{1}$ counterparts) ${ }^{3}$. Another way to modulate colour vision would be to switch between different opsins, a mechanism that we investigate here in the cone photoreceptors of the Pacific pink salmon.

To determine whether it is possible for such a phenotypic transformation to occur: we measured the absorbance of visual pigment along the outer segment of individual cones by using microspectrophotometry ${ }^{3}$ (the outer segment of a cone consists of stacked lipid bilayers that contain the visual pigment $)^{1}$; we also labelled opsin messenger RNAs by using in situ hybridization ${ }^{4}$ with salmon-specific molecular probes.

We found that all the single cones in recently hatched fish (weight about $0.4 \mathrm{~g}$ ) contain a visual pigment with maximum absorbance in the ultraviolet $\left(\lambda_{\max }\right.$ of the visual pigment: $365-375 \mathrm{~nm}$ ); however, as the fish grew (weight exceeding $0.8 \mathrm{~g}$ ), the single cones stopped producing UV-opsin and started to produce blue-opsin $\left(\lambda_{\max }\right.$ of the visual pigment: $425-435 \mathrm{~nm}$ ) in a transformation event that proceeds from the ventral to the dorsal retina.

When absorbance is measured from the tip to the base of a cone outer segment undergoing such a transformation, the absorbance is ultraviolet-dominated at the
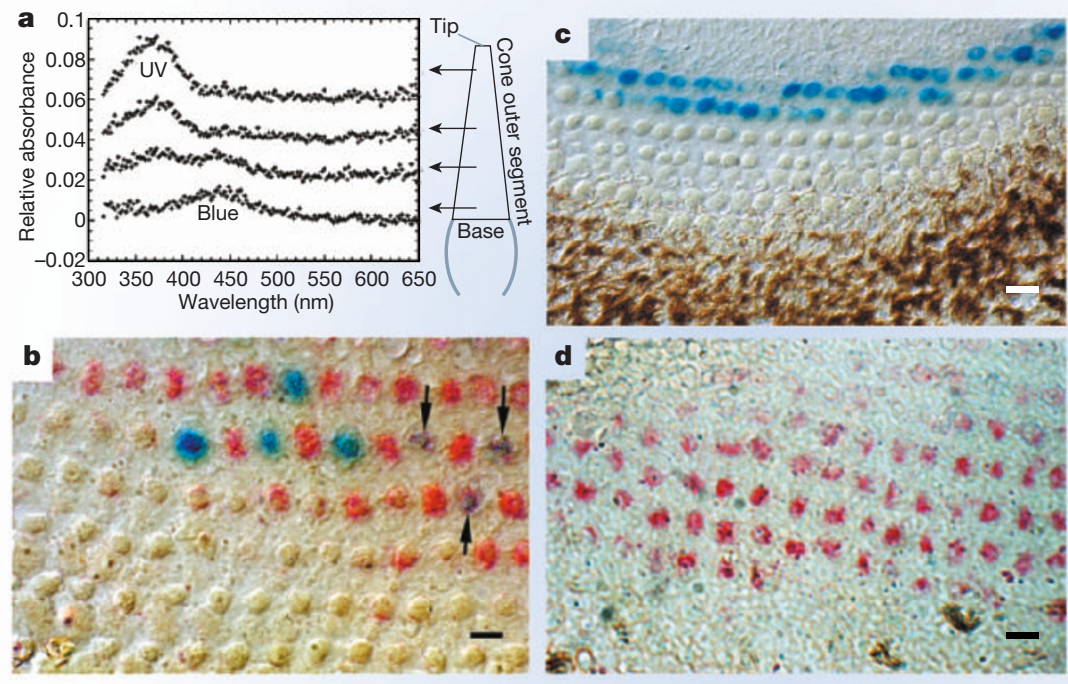

Figure 1 Absorbance measurements and double in situ labelling of single cones in Pacific pink salmon with ultraviolet- and blue-opsin riboprobes. a, Cones show increased absorbance in the ultraviolet at the tip of the outer segment (right) and increased absorbance of blue light at the base, with intermediate absorbances in between (traces are composite averages from seven cones). $\mathbf{b}$, Tangential retinal section showing single cones labelled by in situ hybridization with probes specific for mRNAs encoding UV-opsin (shown in blue) or blue-opsin (in red); cones coexpressing both mRNAs appear purple (arrows). c,d, Single cones are labelled with only the UV-opsin riboprobe before the switch in opsin expression (c), and with only the blue-opsin riboprobe afterwards (d). Scale bars: b, $5.5 \mu \mathrm{m} ; \mathbf{c}, 7.8 \mu \mathrm{m}$; and d, $13 \mu \mathrm{m}$.

tip, becoming blue-dominated at the base (Fig. 1a). As the outer-segment bilayers are produced at the base and removed from the tip ${ }^{5}$, these results show that the UV-opsin is being replaced by blue-opsin during the transformation.

In agreement with this finding, fish in the process of transformation have a mixture of ultraviolet- and blue-sensitive cones, with some cones expressing both opsins together (Fig. 1b). Before the transformation, single cones express only UV-opsin (Fig. 1c); afterwards, they express only blue-opsin (Fig. 1d). Salmonid fish also lose some single (corner) cones following this transformation ${ }^{2}$, further reducing their ultraviolet/blue sensitivity.

This opsin switch in the single cones of pink salmon represents a previously undiscovered way to modulate colour vision. The transformation is linked to a progressive change in the lifestyle of the salmon ${ }^{6}$, which starts as a planktivore in surface waters, where ultraviolet light is abundant, and becomes a fish-eating predator in deeper waters, where blue-green light prevails. As several other vertebrates are known to coexpress different opsins in a cone $\mathrm{e}^{7-10}$, such a mechanism for temporal modulation of colour vision may be widespread.

Christiana L. Cheng,

Iñigo Novales Flamarique

Department of Biological Sciences, Simon Fraser University, Burnaby, British Columbia V5A 1S6, Canada

\section{e-mail:inigo@sfu.ca}

1. Fein, A. \& Szuts, E. Z. Photoreceptors: Their Role in Vision Cambridge University Press, Cambridge, UK, 1982).

2. Kunz, Y. W., Wildenburg, G., Goodrich, L. \& Callaghan, E. Vision Res. 34, 1375-1383 (1994).

3. Hárosi, F. I. Vision Res. 34, 1359-1367 (1994).

4. Forsell, J., Ekström, P., Novales Flamarique, I. \& Holmqvist, B. J. Exp. Biol. 204, 2517-2525 (2001)

5. Besharse, J. C. in The Retina: A Model for Cell Biological Studies Part 1 (eds Aler, R. \& Farber, D.) 297-352 (Academic, New York, 1986).

6. Groot, C. \& Margolis, L. Pacific Salmon Life Histories (UBC Press, Vancouver, 1991).

7. Makino, C. L. \& Dodd, R. L. J. Gen. Physiol. 108, 27-34 (1996). 8. Szél, Á., Van Veen, T. \& Röhlich, P. Nature 370, 336 (1994).

9. Lukáts, Á. et al. Invest. Ophthalmol. Vis. Sci. 43, 2468-2473 (2002)

10. Parry, J. W. L. \& Bowmaker, J. K. Invest. Ophthalmol. Vis. Sci. 43 1662-1665 (2002).

Competing financial interests: declared none.

\section{Buckminsterfullerenes}

\section{A non-metal system for nitrogen fixation}

$\mathrm{n}$ all nitrogen-fixation processes known so far — including the industrial HaberBosch process ${ }^{1}$, biological fixation by nitrogenase enzymes ${ }^{2}$ and previously described homogeneous synthetic systems $s^{3-5}$ - the direct transformation of the stable, inert dinitrogen molecule $\left(\mathrm{N}_{2}\right)$ into ammonia $\left(\mathrm{NH}_{3}\right)$ relies on the powerful redox properties of metals. Here we show that nitrogen fixation can also be achieved by using a non-metallic buckminsterfullerene $\left(\mathrm{C}_{60}\right)$ molecule, in the 
form of a water-soluble $\mathrm{C}_{60}: \gamma$-cyclodextrin (1:2) complex ${ }^{6}$, and light under nitrogen at atmospheric pressure. This metal-free system efficiently fixes nitrogen under mild conditions by making use of the redox properties of the fullerene derivative.

Treatment of a $\gamma$-cyclodextrinbicapped $\mathrm{C}_{60}$ complex $^{6}$ (1 in Fig. 1) with 100 equivalents of sodium bisulphite $\left(\mathrm{Na}_{2} \mathrm{~S}_{2} \mathrm{O}_{4}\right)$ as a reducing reagent in water under 1 atmosphere of nitrogen and with visible light at $60{ }^{\circ} \mathrm{C}$ for 1 hour gave ammonia in $33 \%$ yield (based on the amount of $\mathrm{C}_{60}$ in the reaction); prolonging the reaction time to 24 hours did not increase the yield. The combination of $\mathrm{Na}_{2} \mathrm{~S}_{2} \mathrm{O}_{4}, \mathbf{1}$ and $\mathrm{N}_{2}$ is essential for the reaction, as control reactions lacking any one of these reactants produced no ammonia. Replacing 1 by $\gamma$-cyclodextrin, $\mathrm{C}_{60}$ or a simple mixture of $\mathrm{C}_{60}$ and $\boldsymbol{\gamma}$-cyclodextrin, or performing the reaction at $25^{\circ} \mathrm{C}$, failed to produce ammonia.

The $\mathrm{pH}$ of the reaction must be kept neutral, as yields of ammonia were lower under acidic or basic conditions. When the reaction was carried out under an atmospheric pressure of ${ }^{15} \mathrm{~N}_{2}$, the formation of ${ }^{15} \mathrm{NH}_{4}+{ }^{+}{ }^{15} \mathrm{ND}_{4}^{+} ;-363$ p.p.m. in $\left.\mathrm{D}_{2} \mathrm{O}\right)$ was confirmed by ${ }^{15} \mathrm{~N}$ NMR spectroscopy after acidification of the crude product. This result confirms that molecular nitrogen undergoes conversion into ammonia in this system.

Visible light was also essential to the reaction as no ammonia was formed in the absence of light. An increased yield of ammonia (45\%) was obtained when the reaction mixture was irradiated with a highpressure mercury lamp ( $450 \mathrm{~W})$ without a slit. Strong absorption in the ultraviolet region, with weaker but significant bands in the visible region, was seen in the spectrum of 1 in water: characteristic features of the $\mathrm{C}_{60}$ moiety were observed at wavelengths of 212 (strong), 259 (strong), 333 (strong), 408 (medium), 536 (weak) and 601 (weak) nanometres (results not shown).

These results indicate that charge transfer between nitrogen and the reduced and electronically excited $\mathbf{1}$ (exciplex formation) is probably involved in the reduction of $\mathrm{N}_{2}$, given that $\mathrm{C}_{60}$ and its derivatives are easily excited by low-energy light and that their excited states readily promote electron and energy transfer compared with the groundstate species ${ }^{7}$. Light may therefore assist electron and energy transfer from $\mathrm{C}_{60}$ in $\mathbf{1}$ to $\mathrm{N}_{2}$ (probably coordinated to $\mathbf{1}$ ). A similar effect of light has been described for a transition-metal complex ${ }^{8}$.

We consider that all of the electrons required for the formation of ammonia are supplied by the reduced $\mathrm{C}_{60}$ in $\mathbf{1}$, because $\mathrm{C}_{60}$ in the complex is readily reduced to the corresponding $\mathrm{C}_{60}{ }^{-}$and $\mathrm{C}_{60}{ }^{2-}$ species by using $\mathrm{Na}_{2} \mathrm{~S}_{2} \mathrm{O}_{4}$ (ref. 9). The cyclic voltammogram of 1 (in water under both argon and nitrogen atmospheres) reveals two waves: a reversible

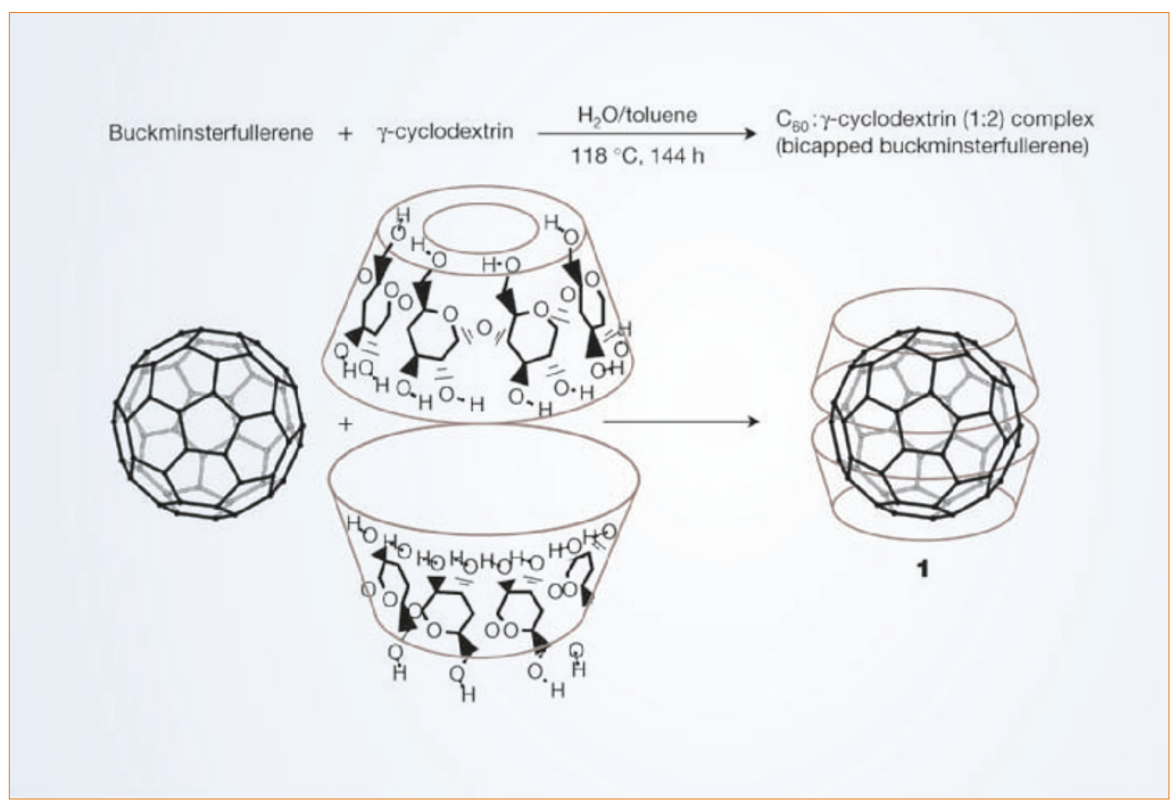

Figure 1 Preparation of $\gamma$-cyclodextrin-bicapped $\mathrm{C}_{60}$ complex (1), which is used in the fixation of nitrogen to ammonia. $A$ mixture of $\mathrm{C}_{60}$ ( $0.400 \mathrm{~g} ; 0.555 \mathrm{mmol}$ ) and $\gamma$-cyclodextrin $\left(1.200 \mathrm{~g} ; 0.925 \mathrm{mmol}\right.$ ) was stirred in a water (160 ml)/toluene $(60 \mathrm{ml})$ mixture at $118^{\circ} \mathrm{C}$ for $48 \mathrm{~h}$ and then $\gamma$-cyclodextrin ( $0.600 \mathrm{~g} ; 0.463 \mathrm{mmol}$ ) was added twice more every $48 \mathrm{~h}$; complex 1 was produced in $70 \%$ yield (1.464 g; $0.391 \mathrm{mmol}$ ) as a purple solid, with each molecule being coordinated with $24 \mathrm{H}_{2} \mathrm{O}$ molecules (stoichiometry from thermogravimetric and differential thermal analysis). In the fixation reaction, a suspension of 1 (37.4 mg; $0.010 \mathrm{mmol}$ ) under 1 atmosphere of nitrogen with $\mathrm{Na}_{2} \mathrm{~S}_{2} \mathrm{O}_{4}(174 \mathrm{mg} ; 1.00 \mathrm{mmol})$ in water $(10 \mathrm{ml})$ was magnetically stirred at $60{ }^{\circ} \mathrm{C}$ for $1 \mathrm{~h}$ under visible light from a fluorescent lamp. The yield of ammonia was quantified by using indophenol reagent.

wave at $-0.61 \mathrm{~V}$ (the half-wave electric potential) assignable to the one-electron redox process $\mathrm{C}_{60} / \mathrm{C}_{60}{ }^{-}$; and an irreversible wave at $-1.09 \mathrm{~V}$ (the cathodic peak potential) assignable to the one-electron redox process $\mathrm{C}_{60}{ }^{-} / \mathrm{C}_{60}{ }^{2-}$. A saturated calomel electrode was used as the reference electrode. The results indicate that the reduced complexes of $\mathbf{1}$ have sufficiently low reduction potentials ${ }^{5}$ to reduce the coordinated $\mathrm{N}_{2}$ molecule.

Some molybdenum and tungsten complexes with nitrogen can be protonated by sulphuric acid to produce ammonia in high yields as a result of the presence of the metal atoms ${ }^{3}$. We therefore investigated whether protonation occurs in $\mathrm{C}_{60}$-coordinated $\mathrm{N}_{2}$. The reaction of 1 with an excess of dilute sulphuric acid under 1 atmosphere of nitrogen at $60{ }^{\circ} \mathrm{C}$ for 1 hour produced ammonia in $15 \%$ yield (based on $\mathrm{C}_{60}$ ). Control experiments run for over 1 hour gave no ammonia at $25^{\circ} \mathrm{C}$, or when $1, \mathrm{H}_{2} \mathrm{SO}_{4}$ or $\mathrm{N}_{2}$ were absent. The yield of ammonia was lower than that obtained in the reaction using $\mathrm{Na}_{2} \mathrm{~S}_{2} \mathrm{O}_{4}$. Visible light was again essential for reaction, with the yield of ammonia being increased to $25 \%$ under a high-pressure mercury lamp (as specified above).

The infrared and Raman spectra of 1 unfortunately showed no clear-cut absorption that could be assigned to the $\nu_{\mathrm{N} \equiv \mathrm{N}}$ band of coordinated $\mathrm{N}_{2}$ on 1 . No peaks other than that due to ${ }^{15} \mathrm{~N}_{2}$ ( -75 p.p.m. in $\mathrm{D}_{2} \mathrm{O}$ ) were observed by ${ }^{15} \mathrm{~N}$ NMR on treatment of 1 in $\mathrm{D}_{2} \mathrm{O}$ under one atmospheric pressure of ${ }^{15} \mathrm{~N}_{2}$. These results indicate that complex formation between $\mathrm{N}_{2}$ and $\mathbf{1}$ is not sufficient to be detected by infrared, Raman and NMR spectroscopy. However, it is possible that molecular $\mathrm{N}_{2}$ might coordinate to the surface of the $\mathrm{C}_{60}$ molecule in $\mathbf{1}$ in an end-on mode.

Yoshiaki Nishibayashi ${ }^{\star}$, Makoto Saito $^{\star}$, Sakae Uemura ${ }^{\star}$, Shin-ichi Takekuma $\dagger$, Hideko Takekuma $\dagger$, Zen-ichi Yoshida $\dagger$

*Department of Energy and Hydrocarbon Chemistry, Graduate School of Engineering, Kyoto University, Yoshida, Sakyo-ku, Kyoto 606-8501, Japan e-mail: uemura@scl.kyoto-u.ac.jp $\dagger$ Department of Applied Chemistry, Faculty of Science and Engineering, Kinki University, 3-4-1 Kowakae, Higashi Osaka, Osaka 577-8502, Japan

1. Appl, M. Ammonia (Wiley-VCH, Weinheim, 1999).

2. Postgate, J. Nitrogen Fixation (Cambridge University Press, Cambridge, 1998).

3. Chatt, J., Pearman, A. J. \& Richards, R. L. Nature 253, 39-40 (1975).

4. Nishibayashi, Y., Iwai, S. \& Hidai, M. Science 279, 540-542 (1998).

5. Yandulov, D. V. \& Schrock, R. R. Science 301, 76-78 (2003).

6. Yoshida, Z., Takekuma, H., Takekuma, S. \& Matsubara, Y. Angew. Chem. Int. Edn 33, 1597-1599 (1994).

7. Guldi, D. M. \& Prato, M. Acc. Chem. Res. 33, 695-703 (2000).

8. Solari, E. et al. Angew. Chem. Int. Edn 40, 3907-3909 (2001).

9. Takekuma, S., Takekuma, H., Matsumoto, T. \& Yoshida, Z. Tetrahedron Lett. 41, 2929-2932 (2000).

Competing financial interests: declared none.

brief communications arising online

www.nature.com/bca

Earth science: An alternative origin for the 'Silverpit crater'

J. R. Underhill (doi:10.1038/nature02476)

Reply: S. A. Stewart \& P. J. Allen

(doi:10.1038/nature02480) 